\title{
URINARY INCONTINENCE DURING PREGNANCY AND DETERMINATION OF THE FACTORS AFFECTING IT
}

\author{
Gizem Citak ${ }^{1}$, Funda Demirturk²
}

\author{
${ }^{1}$ Tokat Gazi Osman Pasa University, Faculty of Health Sciences, Department of Midwifery, Tokat, Turkey \\ 2 Tokat Gazi Osman Pasa University, Faculty of Health Sciences, Department of Physiotherapy, Tokat, Turkey
}

\author{
Address for Correspondence: Gizem Citak, E-mail: gzmakg@hotmail.com \\ Received: 24.02.2021; Accepted: 20.08.2021; Available Online Date: 20.09.2021 \\ (C) Copyright 2021 by Dokuz Eylül University, Institute of Health Sciences - Available online at https://dergipark.org.tr/en/pub/jbachs
}

Cite this article as: Citak G, Demirturk F, Urinary Incontinence During Pregnancy and Determination of the Factors Affecting It. J Basic Clin Health Sci 2021; 3: 36- 42.

\begin{abstract}
Introduction: This study was conducted to determine the prevalence of urinary incontinence in pregnancy and the factors affecting it.

Methods: A total of 300 pregnant women were included. Subjects were examined in terms of physical and sociodemographic characteristics as well as chronic illness status, prenatal and gestational drug use, pelvic trauma and surgical history, chronic cough and smoking, presence of constipation, contraceptive use, obstetric history and urinary incontinence before and during pregnancy. The Sandvik index was used to determine the severity of incontinence in cases having incontinence and the King's Health Questionnaire was used to assess the quality of life of the incontinent.

Results: It was determined that 173 women (\%57.7) had urinary incontinence during their pregnancy; and found that having urinary incontinence prior to pregnancy, use of anti-hypertensive in pregnancy, trimester, dysuria and fullness sensation of bladder before and during pregnancy and difficulty in urination during pregnancy were the factors affecting incontinence in pregnancy $(p<0.05)$. According to the Sandvik index values, it was determined that incontinent women had mild intensity of incontinence and their quality of life was minimally adversely affected by being incontinent; and no correlation was found between the severity of incontinence and quality of life scores ( $p>0.05)$.

Conclusion: Urinary incontinence in pregnancy is affected by neither advanced physical stresses in the current pregnancy nor by the previous obstetric history; but non-mechanical factors such as the maternal genetic structure and/or hormonal and physiological changes are thought to play role in urinary incontinence development.
\end{abstract}

Keywords: Urinary incontinence, Pregnancy, Risk factors, Midwifery.

\section{INTRODUCTION}

Urinary incontinence (UI) which is an important symptom of lower urinary tract dysfunction, is more common in women than in men and the incidence increases with increasing age $(1,2)$.

Risk factors for UI include advanced age, shortness of the urethra, hormonal status and genetic differences as well as pregnancy and birth trauma, early return to severe work pace after birth, recurrent resistant urinary infections, obesity, chronic constipation, smoking, cough, gynecological operations, sedentary life and systemic diseases such as diabetes and pulmonary diseases (3).

The blood flow in the pelvic organs increases with increasing blood volume during pregnancy (4). Hypertrophy occurs in smooth muscles, and 
hyperplasia occurs in the lower urogenital tract mucous membranes. Hormonal changes in pregnancy cause relaxation of the entire musculoskeletal system, especially the pelvis. As a result of the expansion of the uterus over time, the position of the bladder changes and also the volume increases. In this period, frequent urination, night urination, diuresis and incontinence can be observed (4). Physiological and biomechanical changes occurring during pregnancy can prepare the ground for incontinence during pregnancy or may exacerbate the existing problem. In most women, it poses a problem after birth as there was incontinence while pregnancy (2).

Although it is a common problem among pregnant women, most women cannot share such an important problem with the health care worker because of their lack of knowledge about treatment options and the feeling of shame. It is important to increase the knowledge and awareness of midwives who have the chance to follow a pregnant from the very beginning, to determine the situation in the early period and to take the necessary steps. Thus, it will be possible to prevent many problems during pregnancy, postpartum period and even after menopause.

\section{MATERIALS AND METHODS}

A total of 300 pregnant women who applied for routine pregnancy follow-up between 01/02/2017 and $31 / 05 / 2017$ were included in the study in Tokat Gaziosmanpasa University Hospital Gynecology and Obstetrics Clinic. After the physical (age, height, body weight) and socio-demographic characteristics (educational status, occupation) of the pregnant women were recorded, an evaluation form which was prepared for this study was filled in order to determine the incidence of $\mathrm{UI}$ and to investigate the factors

Table 1. Physical characteristics of pregnant women $(n=300)$

\begin{tabular}{ll}
\hline Physical Properties & Mean \pm SD \\
\hline Age (years) & $26.92 \pm 5.39$ \\
Length $(\mathrm{m})$ & $1.61 \pm 0.06$ \\
$\begin{array}{l}\text { Body weight before pregnancy } \\
(\mathrm{kg})\end{array}$ & $62.79 \pm 12.18$ \\
$\begin{array}{l}\text { Body weight during pregnancy } \\
(\mathrm{kg})\end{array}$ & $73.55 \pm 11.56$ \\
$\begin{array}{l}\text { Difference in body index before } \\
\text { pregnancy }(\mathrm{kg})\end{array}$ & $10.76 \pm 6.87$ \\
$\begin{array}{l}\text { Body mass index before } \\
\text { pregnancy }\left(\mathrm{kg} / \mathrm{m}^{2}\right)\end{array}$ & $24.15 \pm 4.58$ \\
Body mass index during & \\
pregnancy $\left(\mathrm{kg} / \mathrm{m}^{2}\right)$ & $28.30 \pm 4.35$ \\
\hline SD: Standart Deviation &
\end{tabular}

affecting it. Women were questioned by means of chronic disease, medication usage before and during pregnancy, history of pelvic trauma and abdominal / pelvic / vaginal surgery, presence of chronic cough, smoking and constipation problem.

Obstetrical history of the cases were evaluated and included gestation time, pregnancy, birth, abortion, dilatation and curettage (D\&C) numbers and delivery type (vaginal, caesarean section), presence of episiotomy and / or perineal tears in cases with vaginal delivery beforehand and whether forceps and / or vacuum were used.

Women were asked if they had involuntary urine loss or not while or before their pregnancy. The conditions. in which UI occurred were investigated to determine the type of incontinence [stress / urgency / stress + urgency (mixed type)].The severity of incontinence was calculated using the Sandvik index. The Turkish validity and reliability study of the index was performed by Hazar and Şirin (5). Incontinent pregnancies were asked how often and how much urine was missed. Multiplication of frequency and intensity gives us the total score where 1-2 points indicate "mild incontinence", 3-6 points indicate "moderate", 8-9 points was recorded as "severe incontinence" and $10-12$ points were recorded as" very severe incontinence". In addition to UI, the presence of fecal incontinence was also questioned. King Health Questionnaire was used to examine the effect of UI on quality of life. The validity and reliability study of the questionnaire was conducted by Kaya et al. in 2015 (6). The questionnaire consists of 9 main sections examining general health status, incontinence effect, limitation levels (role, physical and social), personal relationships, emotions, sleep / energy levels and severity of symptoms. The score ranges between 0-100 and higher scores indicate poor QOL.

Our research was approved by Cumhuriyet University Non-Interventional Clinical Research Ethics Committee with the decision dated 20.01.2017 and 2017-01 / 35. Pregnant women were informed about the study and signed consent forms were provided.

Data were analyzed by SPSS 20.0 package program. Continuous variables were expressed as mean \pm standard deviation and categorical variables as numbers and percentages. The Kolmogorov Smirnov test was used to examine the appropriateness of the data for normal distribution. Mann-Whitney $U$ test was 
Table 2. Number of patients with complaints of stres incontinence,compression type incontinence, mixed incontinence, fecal incontinence, coital incontinence and nokturnal enuresis before and during pregnancy

\begin{tabular}{|c|c|c|c|c|c|c|c|c|c|}
\hline & \multicolumn{4}{|c|}{ Before pregnancy } & \multicolumn{4}{|c|}{ During pregnancy } & \multirow{3}{*}{$* p$} \\
\hline & \multicolumn{2}{|c|}{ Yes } & \multicolumn{2}{|c|}{ No } & \multicolumn{2}{|c|}{ Yes } & \multicolumn{2}{|c|}{ No } & \\
\hline & $\mathbf{n}$ & $\%$ & $\mathbf{n}$ & $\%$ & $\mathbf{n}$ & $\%$ & $\mathbf{n}$ & $\%$ & \\
\hline Stress Incontinence & 103 & 34.3 & 197 & 65.7 & 169 & 56.3 & 131 & 43.7 & 0.0001 \\
\hline Compression Type & 11 & 3.7 & 289 & 96.3 & 21 & 7.0 & 279 & 93.0 & 0.006 \\
\hline \multicolumn{10}{|l|}{ Incontinence } \\
\hline Mixed Incontinence & 8 & 2.7 & 292 & 97.3 & 17 & 5.7 & 283 & 94.3 & 0.004 \\
\hline Fecal Incontinence & 8 & 2.7 & 292 & 97.3 & 28 & 9.3 & 272 & 90.7 & 0.0001 \\
\hline Coital Incontinence & 0 & 0 & 300 & 100 & 2 & 0.7 & 298 & 99.3 & - \\
\hline Nokturnal Enuresis & 7 & 2.3 & 293 & 97.7 & 8 & 2.7 & 292 & 97.3 & 1 \\
\hline
\end{tabular}

*: Mc Nemar test

Table 3. King's Health Questionnaire results of incontinence cases during pregnancy $(n=300)$

\begin{tabular}{lcc}
\hline King's Health Survey Sections & Mean \pm SD & Median (min-max) \\
\hline General Haelth Status & $30.35 \pm 13.36$ & $25(0-75)$ \\
Effect of Incontinence & $31.41 \pm 29.79$ & $33.33(0-100)$ \\
Role Limitation & $22.64 \pm 27.72$ & $0(0-100)$ \\
Physics limitation & $23.7 \pm 27.73$ & $16.67(0-100)$ \\
Social Limitation & $17.79 \pm 23.35$ & $0(0-100)$ \\
Personal Relations & $5.68 \pm 16.22$ & $0(0-100)$ \\
Emotional State & $22.29 \pm 25.96$ & $22.22(0-100)$ \\
Sleep / Energy Level & $36.13 \pm 24.65$ & $33.33(0-100)$ \\
Symptom Severity & $35.3 \pm 18.21$ & $33.33(0-100)$ \\
\hline
\end{tabular}

SD: Standart Deviation

used to compare independent group differences. The differences between the categorical variables were examined by Chi-square analysis (Pearson and Fisher Exact). In addition, McNemar Test was used in dependent group studies in categorical variables. Logistic Regression Analysis was used to determine the risk factors for the disease. Statistical significance level was taken as $p<0.05$.

\section{RESULTS}

Age of the cases ranged between 17 and 44 years and the gestational time was $33.42 \pm 9.43$ weeks. $26(8.7 \%)$ of the pregnant women were in the I. trimester, $22(7.3 \%)$ of them were in the II. trimester; and $252(84 \%)$ were in the III. trimester. The physical characteristics of the cases before and during pregnancy are given in Table 1 .

It was recorded that $10 \%(n=30)$ of the cases had chronic diseases, respectively pulmonary and cardiovascular diseases $(n=9)$, endocrine and metabolic disorders $(n=7)$, autoimmune diseases. ( $n$ $=3$ ), neurological diseases such as migraine, cervical and lumbar disc herniation $(n=5)$, and diseases that do not comply with the above classification such as psychological disorders, dermatological diseases, orthopedic problems $(n=6)$.
$4.7 \%(n=14)$ of the cases stated that they used drugs for various reasons before pregnancy. 6 women used thyroid drugs, 3 used antihypertensives, 2 used antidiabetics, 2 used antianemic, 1 used antidepressant drugs. It was determined that $88.6 \%$ $(n=266)$ of the cases used drugs during pregnancy and the most common of these was vitamins and antianemic drugs $(n=247)$.

It was determined that $173(57.7 \%)$ of the 300 pregnant women had urinary incontinence while their pregnancy period. $106(35.5 \%)$ of the 173 cases stated that they had UI before their pregnancy. In 39 women (13\%) UI were present in their childhood also. Distribution of type of incontinence among cases while and before pregnancy is presented in Table 2 . It can be seen that number of cases having stress incontinence, urgency incontinence and fecal incontinence during pregnancy increased when compared to pre-pregnancy values $(p<0.05)$.

According to the Sandvik Index scores, the majority of 173 pregnant women $(71.1 \%, n=123)$ had mild incontinence. There were moderate incontinence in 32 pregnant women (18.5\%), severe incontinence in 12 pregnant women $(6.9 \%)$, and very severe incontinence in 6 pregnant (3.5\%). 
Table 4. Comparasion of physical characteristics of cases with without urinary incontinence during pregnancy

\begin{tabular}{|c|c|c|c|c|}
\hline \multicolumn{5}{|c|}{ Incontinence in Pregnancy } \\
\hline & $\begin{array}{c}\text { Yes } \\
\text { Mean } \pm \text { SD }\end{array}$ & $\begin{array}{c}\text { No } \\
\text { Mean } \pm \text { SD }\end{array}$ & $\mathbf{z}$ & $\mathbf{p}$ \\
\hline Age (years) & $27.13 \pm 5.66$ & $26.62 \pm 4.99$ & -0.712 & 0.477 \\
\hline Length (m) & $161.15 \pm 5.92$ & $161.46 \pm 6.15$ & -0.405 & 0.686 \\
\hline Body weight before pregnancy (kg) & $62.32 \pm 12.83$ & $63.44 \pm 11.26$ & -1.328 & 0.184 \\
\hline Body weight during pregnancy (kg) & $73.27 \pm 11.41$ & $73.93 \pm 11.8$ & -0.868 & 0.385 \\
\hline Difference in body weight (kg) & $10.95 \pm 6.73$ & $10.49 \pm 7.07$ & -0.987 & 0.323 \\
\hline SMI Pre-pregnancy $\left(\mathrm{kg} / \mathrm{m}^{2}\right)$ & $23.97 \pm 4.6$ & $24.4 \pm 4.56$ & -0.903 & 0.366 \\
\hline SMI during pregnancy $\left(\mathrm{kg} / \mathrm{m}^{2}\right)$ & $28.21 \pm 4.1$ & $28.41 \pm 4.69$ & -0.271 & 0.786 \\
\hline Gestation time (weeks) & $34.23 \pm 8.65$ & $32.33 \pm 10.34$ & -1.047 & 0.295 \\
\hline
\end{tabular}

SMI: Size Mass İndex SD: Standart Deviation $\quad$ z: Mann Whitney U Testi

According to the results of the King's Health Survey, the negative impact of urinary incontinence on quality of life can be seen to be low (Table 3).

Physical properties were similar in pregnant women having incontinence or not $(p>0.5)$ (Table 4). The same condition existed by means of sociodemographic characteristics, also $(p>0.05)$.

Although pregnancies with and without $\mathrm{UI}$ in pregnancy were similar in terms of chronic disease $(\mathrm{n}$ $=17(9.83 \%)$ and $n=13(10.24 \%)(p>0.05)$, they were found to be different in terms of drug use during pregnancy $(p<0.05)$. It has been determined that the use of antihypertensive drugs increases the risk of incontinence.

Although there was no history of pelvic trauma in any of the pregnant women, there also was no significant difference in terms of pelvic or abdominal surgery history in women with and without $\mathrm{UI}$ during pregnancy $(n=56(32.37 \%)$ and $n=39(30.71 \%)(p>$ 0.05).

Continent and incontinent pregnant were similar by means of smoking habits and chronical cough problem $(p>0.05)$.

Pregnant women with and without UI were found to be similar in terms of constipation both pre-pregnancy and during pregnancy. (pre-pregnancy $x^{2}=0.165$; $p>0.05$; during pregnancy $x^{2}=0.026 ; p>0.05$ ).

Women with and without incontinence were similar in terms of gravida, parity, abortion and D\&C ( $p>0.05)$. The age at first birth was found to be $21.59 \pm 4.11$ years for women with incontinence and $21.75 \pm 3.51$ years for those without incontinence $(z=-0.749 ; p=$ $0.454)$. In addition, it was determined that the type of delivery was not a factor affecting incontinence during pregnancy $(p>0.05)$ (Table 5$)$.

In terms of episiotomy, perineal tears and the use of forceps / vacuum, patients with and without incontinence in pregnancy were compared and no significant difference was found ( $p>0.05)$. Continent and incontinent pregnant were similar in terms of large infant birth and multiple pregnancies ( $p>0.05)$.

Pregnant women with and without incontinence were compared in terms of pre-pregnancy incontinence presence and significant difference has been found $(x 2: 120.333 ; p<0.05)$. However, women with $\mathrm{UI}$ and without $\mathrm{UI}$ were similar in terms of $\mathrm{FI}(p>0.05)$.

As a result of the correlation analysis, it was seen that there was no relationship between Sandvik severity index values and King Health Questionnaire scores in women with UI $(n=173)$ during pregnancy $(p>0.05)$ (Table 6).

\section{Factors Affecting Incontinence in Pregnancy}

In the univariate logistic regression analysis, trimester was found to be a factor affecting the incontinence during pregnancy $(p<0.05)$. According to this situation; One unit increase in the trimester increased the risk of urinary incontinence in pregnancy by 1.49 times (95\% Cl: 1.018-2.194).

In the multiple regression model consisting of all significant variables, it was found that only the trimester variable had a statistically significant effect on urinary incontinence in pregnancy $(95 \% \mathrm{Cl}: 1.008$ 2.232; OO: 1.500, p:0.046)

\section{DISCUSSION}

As a result of this study conducted to determine the incidence of $\mathrm{UI}$ and the factors affecting continence during pregnancy, $173(57.7 \%)$ pregnant women out of 300 were found to have UI during pregnancy; and having $\mathrm{UI}$ in pre-pregnancy and antihypertensive usage during pregnancy seemed to be the factors having effect on $\mathrm{Ul}$ existence during pregnancy.

According to a research done by Aydın continent and incontinent pregnants were similar in terms of BMI during pregnancy (7). Wesnes et al., claims that the 
Table 5. Comparasion of previous delivery methods of pregnant women with and without incontinence complaints during pregnancy ( $\mathrm{n}=179$ )

Incontinence in Pregnancy

\begin{tabular}{|c|c|c|c|c|c|c|c|c|}
\hline \multirow[b]{2}{*}{ Birth Type } & \multicolumn{2}{|c|}{ Yes } & \multicolumn{2}{|c|}{ No } & \multicolumn{2}{|c|}{ Total } & \multirow[t]{2}{*}{$x^{2}$} & \multirow[t]{2}{*}{$\mathbf{p}$} \\
\hline & $\mathbf{n}$ & $\%$ & $\mathbf{n}$ & $\%$ & $\mathbf{n}$ & $\%$ & & \\
\hline Vaginal Birth & 61 & 57.55 & 43 & 58.9 & 104 & 58.1 & $0.33 \phi$ & 0.857 \\
\hline Cesarean & 45 & 42.45 & 30 & 41.1 & 75 & 41.9 & & \\
\hline
\end{tabular}

$\mathrm{x}^{2}$ : Ki-kare testi $\phi$ : Pearson Ki-kare Testi

UI will increase on the 30th gestational week if the weight gain is more than $4 \mathrm{~kg}$ till the 15th week; hence there will be no effect of weight gain on UI development between 15th -30th weeks (8). Considering that pre-pregnancy BMI values of the pregnant women in our study are within normal limits and that continent and incontinent pregnants were similar in terms of physical characteristics, it can be said that UI during pregnancy is caused by factors other than physical loadings.

In our study, continent and incontinent women were similar in terms of diseases with systemic effects and potential influence on incontinence.

Song et al. examined the prevalence and risk factors of $\mathrm{UI}$ in their study. Pregnant women having hypertension and diabetes mellitus were found to have more stress incontinence (9). Duignan et al. found $\mathrm{UI}$ existed in 19 of 40 women (48\%) with bronchiectasis (10).

There were similarities between the continent and incontinent pregnant in terms of drug usage before pregnancy $(p>0.05)$. As we investigate the usage of drugs during pregnancy a significant relationship appeared which is thought to depend on antihypertensive drug use. As reported in the literature, it has been suggested that alpha blockers cause vasodilatation to reduce blood pressure and cause an increase in urinary symptoms and incontinence due to loosening the smooth muscles of the bladder neck. Diuretics have also been shown to cause detrusor contraction by causing a large amount of urine to enter the bladder (11).

Bekele et al, found that beforehand cesarean was a risk factor for UI during pregnancy (12). Melville et al. stated that hysterectomy and cesarean section were risk factors for incontinence (13). In our study, vaginal surgery was not detected in any of the cases and it could be said that abdominal surgeries had no negative effect on continence mechanism.

In the literature, it is reported that the incidence of stress incontinence after vaginal delivery is higher than caesarean (14).
Demirturk examined pelvic floor muscle strength of women in different age groups and found that pelvic floor muscle strength of women who had vaginal delivery and cesarean section was similar (15).

In our study, the parameters included in the previous obstetric history (gravida, parity,etc) were not risk factors for incontinence during the current pregnancy, considering the time between the last birth dates of the cases and the current pregnancies $(5.42 \pm 3.29$ years). So, it can be interpreted that the damage that was assumed to occur due to pregnancy and/or birth, etc. in the cases might be healed at the end of long term and the effects on incontinence might be decreased. The 106 (35.3\%) out of 173 cases stated that they had $\mathrm{UI}$ before pregnancy. There was difference between continent and incontinent pregnants in terms of UI before.

\begin{tabular}{lcc}
$\begin{array}{l}\text { Table 6. The relationship between Sandvik incontinence severity } \\
\text { index ang King Health Questionnaire scores }\end{array}$ \\
\hline $\begin{array}{l}\text { King's Health Survey } \\
\text { Sections }\end{array}$ & $\mathbf{r}$ & $\mathbf{p}$ \\
\hline General Health Status & -0.095 & 0.213 \\
Effect of Incontinence & 0.013 & 0.861 \\
Role Limitation & -0.039 & 0.608 \\
Physics limitation & -0.064 & 0.405 \\
Social Limitation & -0.071 & 0.352 \\
Personal Relations & -0.012 & 0.881 \\
Emotional State & -0.095 & 0.212 \\
Sleep / Energy Level & -0.047 & 0.541 \\
Symptom Severity & -0.130 & 0.088 \\
\hline
\end{tabular}

Brown et al. and Riesco et al. have shown that having $\mathrm{UI}$ before is the strongest risk factor of incontinence during current pregnancy $(16,17)$. As the prevalence of UI during pregnancy was not affected by increased physical stress in the current pregnancy or previous obstetric history; it can be suggested that, as also mentioned in Fritel's study; non-mechanical factors such as maternal genetic structure and/or physiological changes and hormonal in pregnancy might play a role in the development of incontinence (18). 
In our study, the most common and frequent complaint was about stress incontinence before and during pregnancy; and the number of cases with stress incontinence, urgency incontinence and fecal incontinence increased significantly with pregnancy. This result might be due to hormonal and physiological changes in pregnancy in addition to the existing genetic structure.

Stress incontinence is reported to be the most common type of incontinence during pregnancy and incidence increases towards the last trimester (19). Urgency type incontinence is the second frequently observed during pregnancy. Pregnancy is a risk factor for fecal incontinence and the pre-pregnancy prevalence increases with pregnancy (20). Collagen weakness (21) or prolonged constipation has been suggested as a cause (20). Although women in both groups were similar in terms of fecal incontinence, our study data also support the results of increasing prevalence in pregnancy.

In our study, it was determined that the trimester which the pregnant woman was in, was a risk factor for incontinence and unit increase in the trimester increased the risk of $\mathrm{UI}$ in pregnancy by 1.49 times. In the multiple regression model consisting of all significant variables, it was found that only trimester variable had a statistically significant effect on $\mathrm{UI}$ in pregnancy.

In the literature, it is reported that the prevalence and severity of incontinence increases with the course of pregnancy. It was shown that the highest incidence was in the second trimester and that the prevalence reached its peak in the third trimester $(22,23,24,25)$. In our study, it was found that women with incontinence had mild $\mathrm{UI}$ and the QOLwas not correlated with incontinence severity.

Kocaöz et al. (26) conducted a study on 208 pregnant women and used The Wagner Life Scale in order to determine $\mathrm{UI}$ and quality of life relation. Despite the fact that the incidence rate was high, the incontinence did not affect or slightly affected the QOL of the pregnant women.

Although UI was seen in more than half of our pregnant women, its mild severity might explain the minimal effect on quality of life.

\section{CONCLUSION}

We can say that UI during pregnancy is a problem in more than half of pregnant women and physical properties (before or during pregnancy) or mechanical loadings do not pose a risk for UI.
Previous obstetric history does not seem to include effects reflected in the current pregnancy, however, there is a correlation between pre-pregnancy presence of incontinence with the current pregnancy prevalence. These results lead us to think that factors such as genetic structure and hormonal, anatomical and physiological differences also play important role in the development of incontinence. Although it is a common problem, the severity of incontinence in our study was mild and the negative impact on quality of life was found to be low. It is a risk factor that the trimester which the pregnant woman in, the changing physiology with the course of pregnancy and it is important to explain its effects on urinary functions. The fact that the trimester was a risk factor may explain the effects of changing physiology of pregnancy on urinary functions.

In our study, the risk factors of incontinence during pregnancy were examined by applying a questionnaire to pregnant women and the fact that the incontinence mechanism associated with risk factors could not be demonstrated by objective methods was the limitation of our study. Further studies including objective assessment tools which will help to establish a healthier relationship comment are required.

Acknowledgements: This study was presented as an oral presentation at 4th International 5th National Midwifery Congress. Conflict of Interest: The authors declare that there are no conflict of interests.

Ethics Committee Approval: The study was approved by Cumhuriyet University Non-Interventional Clinical Research Ethics Committee with the decision dated on 20.01.2017 and 2017-01/35. Financial Disclosure: None declared by the authors.

Peer-review: Externally peer-reviewed.

\section{REFERENCES}

1. Bogner HR, Gallo JJ, Sammel MD, Ford DE, Armenian HK, Eaton WW. Urinary incontinence and psychological distress in community-dwelling older adults. J Am Geriatr Soc 2002; 50: 489-495.

2. https://www.uptodate.com/contents/urinaryincontinence-and-pelvic-organ prolapseassociated-with-pregnancy-and childbirth?source=search_result\&search=urinary $\% 20$ incontinence\&selectedTitle $=6 \sim 1$ Accessed Erişim Tarihi: April 20, 2017.

3. Bilgili N, Akın B, Ege E, Ayaz S. Kadınlarda üriner inkontinans sıklığı ve etkileyen risk faktörleri $T$ Klin J Med Sci 2008; 28(4):487-93. 
4. Davison JM. Upper urinary tract in pregnancy. Stanton., Monga, A. K. (Eds.). Clinical Urogynecology, Churchill Livingstone, London; 2000; 465-470.

5. Hazar Hu, Şirin A. İnkontinans Şiddet İndeksinin Geçerlik Ve Güvenirliği Çalışması. Adü Tıp Fakültesi Dergisi 2008; 9(3):5-8.

6. Kaya S, Akbayrak T, Çelenay ŞT, Dolgun A, Ekici $G$, Beksaç S. Reliability and validity of the Turkish King's Health Questionnaire in women with urinary incontinence. Int Urogynecol J 2015; 26:1853-1859.

7. Aydın Çetindağ N.E. Gebelikte Başlayan Pelvik Taban Bozukluğu Sıklığının Belirlenmesi ve Doğum Sonrası 6. ayda Sebat Eden Olguların Özelliklerinin Öngörülmesi Uzmanlık Tezi; Ankara Üniversitesi Tıp Fakültesi 2016.

8. Wesnes SL, Hunskaar S, Bo K, Rortveit G. Urinary Incontinence and Weight Change During Pregnancy and Postpartum: A Cohort Study. Am J Epidemiol. 2010; 172(9): 1034-1044.

9. Song Y, Zhang W, Song J, Bo X. Prevalence and risk factors of urinary incontinence in Fuzhou Chinese women, Chin. Med. J 2005;118, 887892.

10. Duignan N, McDonnell MJ, Mokoka MC, Rutherford RM. High prevalence of stress urinary incontinence in adult patients with bronchiectasis. Ir Med J. Aug 2016; 8;109(7):440.

11. Steele AC, Kohli N, Mallipeddi $P$, Karram M. Pharmacologic causes of female incontinence. Int Urogynecol J Pelvic Floor Dysfunct 1999; 10(2):106-10.

12. Bekele $A$, Adefris $M$ and Demeke S. Urinary incontinence among pregnant women, following antenatal care at University of Gondar Hospital, North West Ethiopia. BMC Pregnancy and Childbirth 2016; 16:333 DOI 10.1186/s12884016-1126-2.

13. Melville JL, Katon W, Delaney K, Newton K. Urinary incontinence in US women: a populationbased study. Arch Intern Med 2005; 165(5):537542.

14. Kokabi R, Yazdanpanah D. Effects of delivery mode and sociodemographic factors on postpartum stress urinary incontinency in primipara women: A prospective cohort study.J Chin Med Assoc. Aug 2017; 80(8):498-502.

15. Demirtürk F. Çeşitli Yaş Dönemlerinde Pelvik Taban Kas Kuvvetini Etkileyen Faktörlerin
Incelenmesi, Doktora Tezi; Hacettepe Üniversitesi Sağlık Bilimleri Enstitüsü 2006.

16. Brown SJ, Donath S, MacArthur C, McDonald $\mathrm{EA}$, Krastev $\mathrm{AH}$. Urinary incontinence in nulliparous women before and during pregnancy: prevalence, incidence, and associated risk factors. Int Urogynecol J 2010; 21(2):193-202.

17. Riesco ML, Fernandes-Trevisan K, Leister N, Cruz Cda S, Caroci Ade S, Zanetti MR. Urinary incontinence related to perineal muscle strength in the first trimester of pregnancy: cross-sectional study. Rev Esc Enferm USP 2014; 48(Esp):32-8.

18. Fritel $X$, Fauconnier A, Levet $C$, Bénifla JL. Stress urinary incontinence 4 years after the first delivery: a retrospective cohort survey. Acta Obstet Gynecol Scand 2004; 83:941-5.

19. Franco EM, Pare' s D, Colome'NL, Paredes JRMa, Tardiu LA. Urinary incontinence during pregnancy. Is there a difference between first and third trimester? European Journal of Obstetrics \& Gynecology and Reproductive Biology 2014;182 86-90.

20. Kızılkaya Beji N. İdrar kaçırma ve organ sarkmalarından korunma: Sağlıklı yaşam biçimi davranışları. The Fisrst Balkac Pelvic Floor Dysfunction Syposium; Apr 1 2001. Edirne Turkey.

21. Chaliha C., et al. Anal function: effect of pregnancy and delivery. Am J Obstet Gynecol 2001; 185(2): p. 427-32.

22. Thorp JM Jr, Norton PA, Wall LL, et al. Urinary incontinence in pregnancy and the puerperium: a prospective study. Am J Obstet Gynecol 1999; 181:266.

23. Viktrup L, Lose $G$. The risk of stress incontinence 5 years after first delivery. Am J Obstet Gynecol 2001; 185:82.

24. Van Brummen $\mathrm{HJ}$, et al. Defecatory symptoms during and after the first pregnancy: prevalences and associated factors. Int Urogynecol J Pelvic Floor Dysfunct 2006; 17(3): p. 224-30.

25. Solans-Domènech $M$, Sánchez $E$, Espuña-Pons M. Urinary and anal incontinence during pregnancy and postpartum: incidence, severity, and risk factors. Obstet Gynecol 2010; 115(3):618-28.

26. Kocaöz S, Talas MS, and Atabekoğlu CS. Urinary incontinence in pregnant women and their quality of life. Journal of clinical nursing 2010; 19(23-24): p.3314-3323. 